\title{
Identification of Glass and Ceramics by X-ray Fluorescence Analysis with a Pyroelectric X-ray Generator
}

\author{
Hiroyuki IDA ${ }^{* * * \dagger}$ and Jun KAWAI* \\ *Department of Materials Science and Engineering, Kyoto University, Sakyo-ku, Kyoto 606-8501, Japan \\ **Forensic Science Laboratory, Kyoto Pref. Police H.Q., Kamigyo-ku, Kyoto 602-8550, Japan
}

\begin{abstract}
Applications of X-ray fluorescence (XRF) analysis with a pyroelectric X-ray generator are presented. Glass and ceramics were analyzed with this novel X-ray generator to examine its capability for analyzing nonmetallic inorganic material. Although the power of X-ray output was a few orders of magnitude lower than conventional X-ray tubes, many elements such as $\mathrm{Si}, \mathrm{K}, \mathrm{Ca}, \mathrm{Ti}, \mathrm{Cr}, \mathrm{Fe}, \mathrm{Zn}, \mathrm{Sr}, \mathrm{Ba}$, and $\mathrm{Pb}$ were detected in glass and ceramic samples. Light elements such as $\mathrm{Na}$, $\mathrm{Mg}$, and $\mathrm{Al}$ were not detected because of the low fluorescence yield and the absorption of fluorescent X-rays in air. The elements detected or the relative peak intensities of the elements were different from each other, and the samples analyzed were identified by the XRF spectrum, notwithstanding the low power of the X-ray output. This novel device showed the sufficient capability for preliminary screening before strict identification of analytes. The pyroelectric X-ray generator can also be used to analyze large samples that cannot be put into ordinary XRF spectrometers because the device has no dimensional limitation of analytes.
\end{abstract}

(Received May 10, 2004; Accepted June 29, 2004)

\section{Introduction}

Because of the development of analytical techniques in recent years, high sensitivity analysis has become possible with synchrotron radiation or with a total reflection X-ray fluorescence (XRF) spectrometer. The need for higher sensitivity analysis is still large. Therefore studies on the improvement of analytical techniques are important. On the other hand, high sensitivity is not always needed in daily analysis; e.g. preliminary screening, where easiness or low cost of measurement is preferable to the sensitivity of analysis. A portable X-ray generator contributes to the convenience of an XRF spectrometer.

Recently, a novel X-ray generator using a charging phenomenon has become commercially available; it has small dimensions, $15 \mathrm{~mm}$ in diameter and $10 \mathrm{~mm}$ in height. When equipped with a controller box that holds a $9 \mathrm{~V}$ dry battery, the dimensions of the device are $125 \mathrm{~mm}$ in length, $45 \mathrm{~mm}$ in width, and $30 \mathrm{~mm}$ in height. Kawai et al. ${ }^{1}$ reported that the pressure of residual gas in an X-ray tube was the most important parameter for the X-ray emission by charged insulators. Brownridge, ${ }^{2}$ and Brownridge and Raboy ${ }^{3}$ reported that cyclic heating and cooling of pyroelectric crystals, such as $\mathrm{LiTaO}_{3}$, $\mathrm{LiNbO}_{3}$ and $\mathrm{CsNO}_{3}$, in an atmosphere of low-pressure gas generated electrons and ions, and that X-rays were generated by collision of the electrons with a metal target and the crystal. The pyroelectric X-ray generator has characteristics such as dry battery drive, low power and periodically changing X-ray output. Kawai et al. ${ }^{4}$ reported analysis of metal oxide with the pyroelectric X-ray generator. We have reported the detection of small amounts of $\mathrm{Fe}$ in aluminum foil, ${ }^{5}$ and quantitative analysis

$\doteqdot$ To whom correspondence should be addressed.

E-mail: ida@kpp.mbox.media.kyoto-u.ac.jp of $\mathrm{Cr}$ in steel. ${ }^{6}$ These reports indicated the capability for metal analysis. The analysis of leather ${ }^{7}$ was reported, which indicated the capability of analyzing organic material.

In this study, the capability of analyzing nonmetallic inorganic material is examined by analyzing glass and ceramics. Glass and ceramics have often been analyzed by XRF spectrometry owing to non-destructiveness of such measurement. In forensic science, it is of great importance to analyze evidential objects without deformation or destruction. In art and archaeology, unique and valuable objects should be analyzed without causing any damage to the artifact. However, destructive analysis is sometimes added to XRF analysis to obtain detailed information on the composition of the object. Applications by XRF, ${ }^{8-10}$ total-reflection XRF, ${ }^{11,12} \mathrm{XRF}$ and electron probe microanalysis (EPMA), ${ }^{13,14}$ XRF, X-ray diffraction, thermal analysis and voltammetry, ${ }^{15} \mathrm{XRF}$ and neutron activation analysis, ${ }^{16} \mathrm{XRF}$, EPMA and atomic absorption spectroscopy, ${ }^{17}$ were reported on the analysis of glass and ceramics. With regard to X-ray sources, a radioisotope was used to analyze ceramics ${ }^{18}$ along with X-ray tubes. The aim of this study is to examine whether the pyroelectric X-ray generator can be used to detect major elements in glass and ceramics by direct analysis of the analyte.

\section{Experimental}

The X-ray generator used was a Cool-X (Amptec, Bedford, MA, USA). The pyroelectric crystal in Cool- $X$ was $\mathrm{LiTaO}_{3}$ and the target metal was $\mathrm{Cu}$. Because production of X-rays needed a temperature change of the pyroelectric crystal, it was necessary to heat and cool the crystal by a Peltier heater and cooler. The X-ray output also changed periodically through that cycle. X-rays were not generated when shifting from heating to cooling and from cooling to heating. The cycle time was about 2 min. The electric power applied to Peltier heating and cooling 
Table 1 The glass samples analyzed and elements detected by Cool-X and SEA5120

\begin{tabular}{|c|c|c|}
\hline Sample & Cool-X & SEA5120 \\
\hline Quartz cuvet & $\mathrm{Si}$ & $\mathrm{Si}$ \\
\hline Test tube 1 (brown) & $\mathrm{Si}, \mathrm{K}, \mathrm{Ca}, \mathrm{Ti}, \mathrm{Fe}, \mathrm{Sr}$ & $\begin{array}{l}\mathrm{Na}, \mathrm{Al}, \mathrm{Si}, \mathrm{K}, \mathrm{Ca}, \mathrm{Ti}, \\
\mathrm{Fe}, \mathrm{Rb}, \mathrm{Sr}, \mathrm{Ba}\end{array}$ \\
\hline Test tube 2 & $\mathrm{Si}, \mathrm{K}, \mathrm{Ca}, \mathrm{Fe}, \mathrm{Ba}$ & $\begin{array}{l}\mathrm{Na}, \mathrm{Al}, \mathrm{Si}, \mathrm{K}, \mathrm{Ca} \\
\mathrm{Fe}, \mathrm{Rb}, \mathrm{Sr}, \mathrm{Ba}\end{array}$ \\
\hline Test tube 3 & $\mathrm{Si}, \mathrm{K}, \mathrm{Ca}, \mathrm{Fe}, \mathrm{Ba}$ & $\begin{array}{l}\mathrm{Na}, \mathrm{Al}, \mathrm{Si}, \mathrm{K}, \mathrm{Ca} \\
\mathrm{Fe}, \mathrm{As}, \mathrm{Rb}, \mathrm{Sr}, \mathrm{Ba}\end{array}$ \\
\hline Cover glass & $\mathrm{Si}, \mathrm{K}, \mathrm{Ti}, \mathrm{Zn}$ & $\begin{array}{l}\mathrm{Na}, \mathrm{Al}, \mathrm{Si}, \mathrm{K}, \mathrm{Ti}, \mathrm{Fe}, \\
\mathrm{Zn}, \mathrm{Sb}\end{array}$ \\
\hline Slide glass & $\mathrm{Si}, \mathrm{K}, \mathrm{Ca}, \mathrm{Zn}, \mathrm{Ba}$ & $\begin{array}{l}\mathrm{Na}, \mathrm{Si}, \mathrm{K}, \mathrm{Ca}, \mathrm{Fe}, \\
\mathrm{Zn}, \mathrm{Sr}, \mathrm{Sb}, \mathrm{Ba}\end{array}$ \\
\hline Pipette & $\mathrm{Si}, \mathrm{K}, \mathrm{Ca}, \mathrm{Ba}$ & $\begin{array}{l}\mathrm{Na}, \mathrm{Al}, \mathrm{Si}, \mathrm{K}, \mathrm{Ca} \\
\mathrm{Fe}, \mathrm{As}, \mathrm{Rb}, \mathrm{Sr}, \mathrm{Ba}\end{array}$ \\
\hline Sheet glass & $\mathrm{Si}, \mathrm{Ca}, \mathrm{Fe}$ & $\begin{array}{l}\mathrm{Na}, \mathrm{Mg}, \mathrm{Si}, \mathrm{K}, \mathrm{Ca}, \\
\mathrm{Ti}, \mathrm{Fe}, \mathrm{Rb}, \mathrm{Sr}\end{array}$ \\
\hline Bottle (green) & $\mathrm{Si}, \mathrm{Ca}, \mathrm{Cr}, \mathrm{Fe}$ & $\begin{array}{l}\mathrm{Na}, \mathrm{Si}, \mathrm{K}, \mathrm{Ca}, \mathrm{Cr} \\
\mathrm{Fe}, \mathrm{Rb}, \mathrm{Sr}, \mathrm{Pb}\end{array}$ \\
\hline
\end{tabular}

was less than $300 \mathrm{~mW}$. The pyroelectric crystal (thickness $\sim$ mm) was electrified up to $\sim 30 \mathrm{kV}$ by changing the temperature. The temperature range in Cool- $\mathrm{X}$ was unknown (in Brownridge's paper, from $\sim 0^{\circ} \mathrm{C}$ to $\sim 100^{\circ} \mathrm{C}$ ). This X-ray generator emitted $\mathrm{X}$-rays that consisted of $\mathrm{Ta} \mathrm{L}$ and $\mathrm{Cu} \mathrm{K}$ lines and bremsstrahlung radiation, in a large solid angle from a $\mathrm{Be}$ window $9 \mathrm{~mm}$ in diameter. $\mathrm{Cu} \mathrm{K} \mathrm{K}_{\alpha}$ line overlapped $\mathrm{Ta}_{\alpha}$ line and they formed one peak at about $8 \mathrm{keV}$. The details of this $\mathrm{X}$ ray generator are described elsewhere. ${ }^{1}$

The emitted fluorescence radiation from the sample was detected by a silicon drift detector (Ourstex, Neyagawa, Japan) with Ketek silicon drift module of $5 \mathrm{~mm}^{2}$ effective detection area, $300 \mu \mathrm{m}$ crystal thickness, and an energy resolution of 160 $\mathrm{eV}$ for $5.9 \mathrm{keV} \mathrm{X}$-rays. The detector was equipped with an 8 $\mu \mathrm{m}$ thick Be window and a $\mathrm{Zr}$ collimator $2.4 \mathrm{~mm}$ in diameter.

The geometry between the X-ray generator and the detector was fixed at $90^{\circ}$. A sample was placed at a distance of $1.5 \mathrm{~cm}$ from both the X-ray generator and the detector. The wide X-ray flux (diameter $\geqq 9 \mathrm{~mm}$ ) irradiated the sample without a collimator. Considering the solid angle for the irradiated area on the sample, a simple geometry of $90^{\circ}$ was chosen.

All measurements by the pyroelectric X-ray generator were performed in air for $1000 \mathrm{~s}$. This measurement time covered several cycles of heating and cooling of the pyroelectric crystal. The peak intensity increased according to the duration of the measurement, and $1000 \mathrm{~s}$ was enough time to identify the peak. The signals from the detector were taken into a digital signal processor and each spectrum was analyzed after a Savitzky-Golay smoothing procedure ${ }^{19,20}$ (second order, 11 points, 10 iterations, one channel corresponded to $8.4 \mathrm{eV}$ ).

For comparison, glass samples were also analyzed with an XRF spectrometer SEA5120 (Seiko Instruments, Chiba, Japan). This spectrometer consisted of a molybdenum target X-ray tube, a collimator and a $\mathrm{Si}(\mathrm{Li})$ detector with $6 \mathrm{~mm}$ effective detection diameter, with an energy resolution of $155 \mathrm{eV}$ for $5.9 \mathrm{keV} \mathrm{X}$ rays. The X-ray tube was used at $45 \mathrm{kV}, 44-64 \mu \mathrm{A}$ (automatically set current). The collimator of $1.8 \mathrm{~mm}$ in diameter was used. All measurements by SEA5120 were performed in vacuum for $300 \mathrm{~s}$ and each spectrum was analyzed with a software package that was normally installed in the spectrometer. Ceramic samples could not be analyzed by SEA5120 because the size of the ceramic samples was larger
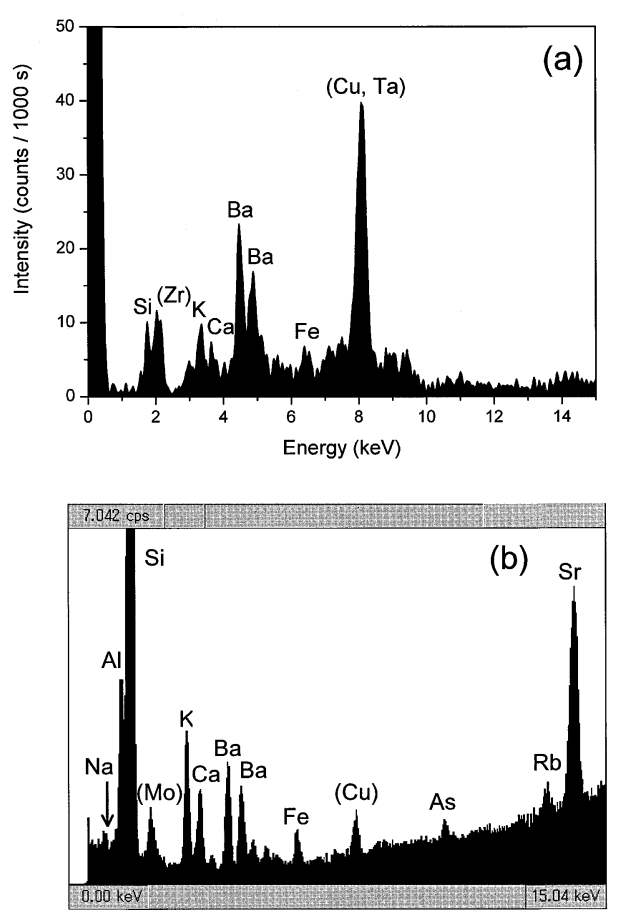

Fig. 1 XRF spectra of Test tube 3. (a) Spectrum by Cool-X, (b) Spectrum by SEA5120. Zr, Cu, Ta and Mo are shown in parentheses because these elements originated from the device.

than the space to hold the analyte and the ceramic samples could not be put into this spectrometer.

\section{Results and Discussion}

\section{Glass}

The list of glass samples analyzed in this study and the elements detected by Cool-X and SEA5120 are presented in Table 1. In Table 1, Quartz cuvet was quartz glass, Test tubes and Cover glass were borosilicate glass and the others were soda-lime glass. The constituent of quartz glass was $\mathrm{SiO}_{2}$, and only Si was detected in Quartz cuvet. The elements detected by SEA5120 were $\mathrm{Na}, \mathrm{Mg}, \mathrm{Al}, \mathrm{Si}, \mathrm{K}, \mathrm{Ca}, \mathrm{Ti}, \mathrm{Cr}, \mathrm{Fe}, \mathrm{Zn}, \mathrm{As}, \mathrm{Rb}$, $\mathrm{Sr}, \mathrm{Sb}, \mathrm{Ba}$, and $\mathrm{Pb}$. As exists widely in minerals, and is contained in glass as an impurity. $\mathrm{Cr}$ in Bottle was a green color agent. Among these elements, Cool-X did not detect light elements such as $\mathrm{Na}, \mathrm{Mg}$, and $\mathrm{Al}$. Although glass contains much $\mathrm{Si}$, the peak intensity of $\mathrm{Si}$ by Cool-X was small in all samples. Elements of low atomic number were difficult to detect because of low fluorescence yield and absorption of fluorescent X-rays in air.

The content of each element detected by SEA5120 was calculated with the fundamental parameter method. Because this spectrometer could not detect light elements such as B (contained in borosilicate glass) and $\mathrm{O}$ (contained in all glass as oxide), the content was a relative content of the detected elements that did not include $\mathrm{B}$ and $\mathrm{O}$. The contents of $\mathrm{K}, \mathrm{Ca}$, $\mathrm{Ti}, \mathrm{Cr}, \mathrm{Fe}, \mathrm{Zn}, \mathrm{As}, \mathrm{Rb}, \mathrm{Sr}, \mathrm{Sb}, \mathrm{Ba}$ and $\mathrm{Pb}$ in all samples except Quartz cuvet are listed in Table 2, with the result of detection by Cool-X. $0.93 \%$ K (in Sheet glass) and $1.72 \%$ K (in Bottle) was not detected, whereas $\mathrm{Ca}$ was detected when the content was less than $1 \%$ (in Test tubes 1,2 , and 3 ). The sensitivity for $\mathrm{K}$ was lower than the sensitivity for $\mathrm{Ca}$ owing to the lower fluorescence yield and the larger absorption in air. The reason 
Table 2 The content of elements detected by SEA5120

\begin{tabular}{|c|c|c|c|c|c|c|c|c|c|c|c|c|}
\hline Sample & K & $\mathrm{Ca}$ & $\mathrm{Ti}$ & $\mathrm{Cr}$ & $\mathrm{Fe}$ & $\mathrm{Zn}$ & As & $\mathrm{Rb}$ & $\mathrm{Sr}$ & $\mathrm{Sb}$ & $\mathrm{Ba}$ & $\mathrm{Pb}$ \\
\hline Test tube 1 & 2.83 & 0.99 & 3.28 & & 0.95 & & & $0.01^{\mathrm{a}}$ & 0.10 & & $0.73^{\mathrm{a}}$ & \\
\hline Test tube 2 & 2.56 & 0.99 & & & 0.06 & & & $0.01^{\mathrm{a}}$ & $0.06^{\mathrm{a}}$ & & 0.55 & \\
\hline Test tube 3 & 2.37 & 0.88 & & & 0.05 & & $0.01^{\mathrm{a}}$ & $0.01^{\mathrm{a}}$ & $0.06^{\mathrm{a}}$ & & 0.65 & \\
\hline Cover glass & 9.01 & & 3.32 & & $0.02^{\mathrm{a}}$ & 8.65 & & & & $0.05^{\mathrm{a}}$ & & \\
\hline Slide glass & 9.30 & 6.89 & & & $0.03^{\mathrm{a}}$ & 4.28 & & & $0.06^{\mathrm{a}}$ & $0.36^{\mathrm{a}}$ & 1.57 & \\
\hline Pipette & 3.81 & 5.20 & & & $0.03^{\mathrm{a}}$ & & $0.05^{\mathrm{a}}$ & $0.02^{\mathrm{a}}$ & $0.05^{\mathrm{a}}$ & & 1.10 & \\
\hline Sheet glass & $0.93^{\mathrm{a}}$ & 8.33 & $0.09^{a}$ & & 0.19 & & & $0.01^{\mathrm{a}}$ & $0.01^{\mathrm{a}}$ & & & \\
\hline Bottle & $1.72^{\mathrm{a}}$ & 12.40 & & 0.16 & 0.13 & & & $0.01^{\mathrm{a}}$ & $0.02^{\mathrm{a}}$ & & & $0.02^{\mathrm{a}}$ \\
\hline
\end{tabular}

a. Not detected by Cool-X. All data in wt $\%$. Note that these values are relative contents of the elements excluding B and O.

for non-detection of $1.72 \% \mathrm{~K}$ (in Bottle) was that $\mathrm{K} \mathrm{K}_{\alpha}$ line overlapped the shoulder of $12.40 \% \mathrm{Ca}_{\alpha}$ line. $0.16 \% \mathrm{Cr}$ (in Bottle) and $0.05 \% \mathrm{Fe}$ (in Test tube 3) were detected. The high sensitivity for $\mathrm{Cr}$ and $\mathrm{Fe}$ was owing to effective excitation by $\mathrm{Ta}$ $\mathrm{L}_{\alpha}$ and $\mathrm{Cu} \mathrm{K}_{\alpha}$ lines. $0.10 \% \mathrm{Sr}$ (in Test tube 1) was detected. The high sensitivity for $\mathrm{Sr}$ was due to low background around Sr K $\mathrm{K}_{\alpha}$ line. $0.73 \% \mathrm{Ba}$ (in Test tube 1) was not detected, whereas $0.55 \% \mathrm{Ba}$ (in Test tube 2) was detected. The reason for nondetection of $0.73 \% \mathrm{Ba}$ (in Test tube 1) was that Test tube 1 contained $\mathrm{Ti}$, and the $\mathrm{Ba} \mathrm{L}$ line overlapped $\mathrm{Ti} \mathrm{K}$ line. Ba in Test tube 1 was detected by SEA5120 because Ba K line appeared in the spectrum. This indicated the advantage of analysis with high energy $\mathrm{X}$-rays. $\mathrm{As}, \mathrm{Rb}, \mathrm{Sb}$, and $\mathrm{Pb}$ were not detected by Cool-X owing to the low content of these elements in glass samples. The detection limit (MDL) for each element detected was calculated according to the expression MDL $=3 B^{1 / 2}(C / N)$, where $B=$ background counts, $N=$ net counts, $C=$ content of the element. The MDL for each element were as follows: $\mathrm{K}$, $1.25 \%$; Ca, $0.36 \%$; Ti, 0.44\%; Cr, $0.11 \%$; Fe, $0.05 \%$; Zn, $0.46 \% ; \mathrm{Sr}, 0.07 \% ; \mathrm{Ba}, 0.27 \%$. Though the sensitivity depends on the element, this result shows that elements (excluding light elements such as $\mathrm{B}, \mathrm{O}, \mathrm{Na}, \mathrm{Mg}$, and $\mathrm{Al}$ ) in glass can generally be detected by Cool-X when the content is sub-percentage level. Spectra of Test tube 3 by Cool-X and SEA5120 are presented in Figs. 1 (a) and (b), respectively, to show detection of $2.37 \% \mathrm{~K}$, $0.88 \% \mathrm{Ca}, 0.05 \% \mathrm{Fe}$, and $0.65 \% \mathrm{Ba}$ by Cool-X, and to show the difference of the spectra by Cool-X and SEA5120. The large peak intensity of $\mathrm{Sr}$ by SEA5120 was owing to effective excitation by Mo $\mathrm{K}_{\alpha}$ line. The increasing background at $\mathrm{Sr}$ in Fig. 1 (b) is a shoulder of Compton scattering of Mo $\mathrm{K}_{\alpha}$ line.

Table 1 shows that the elements detected in each sample are different from one another except Test tube 2 and Test tube 3 . When the elements detected are different, the samples can easily be identified, i.e. whether the two samples are the same or not can be concluded. The same elements ( $\mathrm{Si}, \mathrm{K}, \mathrm{Ca}, \mathrm{Fe}$, and $\mathrm{Ba}$ ) were detected in Test tube 2 and Test tube 3, where the relative peak intensity of $\mathrm{Ba}$ was different from each other. When the relative peak intensity of an element is different, the samples can be identified even when the same elements are detected. Though the number of elements detected by Cool-X is less than the number of elements detected by SEA5120, identification of all the glass samples analyzed can be carried out on the basis of spectrum difference. Representative spectra of Quartz cuvet, Test tube 1, Slide glass and Bottle are presented in Fig. 2 to show detection of $\mathrm{Si}, \mathrm{K}, \mathrm{Ca}, \mathrm{Ti}, \mathrm{Cr}, \mathrm{Fe}, \mathrm{Sr}$, and $\mathrm{Ba}$.

\section{Ceramics}

The list of the ceramic samples analyzed in this study, and the elements detected by Cool-X are presented in Table 3. All measurements were performed on areas where there was no
Table 3 The ceramic samples analyzed and elements detected by Cool-X

\begin{tabular}{ll}
\hline \multicolumn{1}{c}{ Sample } & \multicolumn{1}{c}{ Element } \\
\hline Cup 1, Dish 1 & $\mathrm{Si}, \mathrm{K}, \mathrm{Fe}$ \\
Cup 2, Cup 3, Dish 2 & $\mathrm{Si}, \mathrm{K}, \mathrm{Ca}, \mathrm{Fe}$ \\
Cup 4, Dish 3, Dish 4 & $\mathrm{Si}, \mathrm{K}, \mathrm{Ca}, \mathrm{Fe}, \mathrm{Zn}$ \\
Cup 5 & $\mathrm{Si}, \mathrm{K}, \mathrm{Ca}, \mathrm{Fe}, \mathrm{Zn}, \mathrm{Ba}$ \\
Cup 6 & $\mathrm{Si}, \mathrm{K}, \mathrm{Ca}, \mathrm{Ti}, \mathrm{Fe}, \mathrm{Zn}, \mathrm{Pb}$ \\
Cup 7 & $\mathrm{Si}, \mathrm{Ca}, \mathrm{Ba}, \mathrm{Pb}$ \\
Dish 5 & $\mathrm{Si}, \mathrm{K}, \mathrm{Ca}, \mathrm{Fe}, \mathrm{Ba}, \mathrm{Pb}$ \\
Dish 6 & $\mathrm{Si}, \mathrm{K}, \mathrm{Ca}, \mathrm{Ti}, \mathrm{Fe}$ \\
\hline
\end{tabular}

painting to avoid detecting elements in pigments. Because there was an enamel layer on the surface of these ceramic samples, elements detected by XRF analysis were mainly the elements in the enamel rather than the foundation clay. The constituent of enamel is similar to glass. $\mathrm{Si}, \mathrm{K}, \mathrm{Ca}, \mathrm{Ti}, \mathrm{Fe}, \mathrm{Zn}, \mathrm{Ba}$, and $\mathrm{Pb}$ were detected in the ceramic samples. $\mathrm{Pb}$ in ceramics is an element that has been intentionally added in enamel as an additive. On the other hand, $\mathrm{Pb}$ in glass is ordinarily an impurity, except for lead glass. Therefore the content of $\mathrm{Pb}$ in ceramics whose enamel contains lead compound as an additive is much higher than the content in glass. This is the reason why $\mathrm{Pb}$ was not detected in glass and was detected in ceramics by Cool-X. Though the same elements ( $\mathrm{Si}, \mathrm{K}$, and $\mathrm{Fe}$ ) were detected in Cup 1 and Dish 1, the relative peak intensities of these elements were different from each other and these samples were easily identified by the XRF spectrum. Cup 2, Cup 3, Dish 2, and Cup 4, Dish 3, Dish 4 were also identified respectively by a similar reason. The elements detected in other samples (Cup 5, Cup 6, Cup 7, Dish 5, and Dish 6) were different from one another. Therefore identification of all the ceramic samples analyzed can be carried out on the basis of spectrum difference. Representative spectra of Dish 5 and Dish 6 are presented in Fig. 3 to show detection of $\mathrm{Si}, \mathrm{K}, \mathrm{Ca}, \mathrm{Ti}, \mathrm{Fe}$, $\mathrm{Ba}$, and $\mathrm{Pb}$

In this study, ceramic samples (cups and dishes) could not be analyzed by a conventional XRF spectrometer due to the incapability of putting a large analyte into the spectrometer. A portable X-ray generator has no limitation on sample dimensions. Large samples can be analyzed with a portable device. Moreover, analysis can be carried out on all the analytes of various forms because an X-ray generator and a detector can take arbitrary geometry according to each analyte. If a cup-shaped analyte is larger than the X-ray generator and the detector, analysis on areas inside the sample is possible, where a conventional XRF spectrometer cannot analyze. Portable devices have such advantages, although measurement 

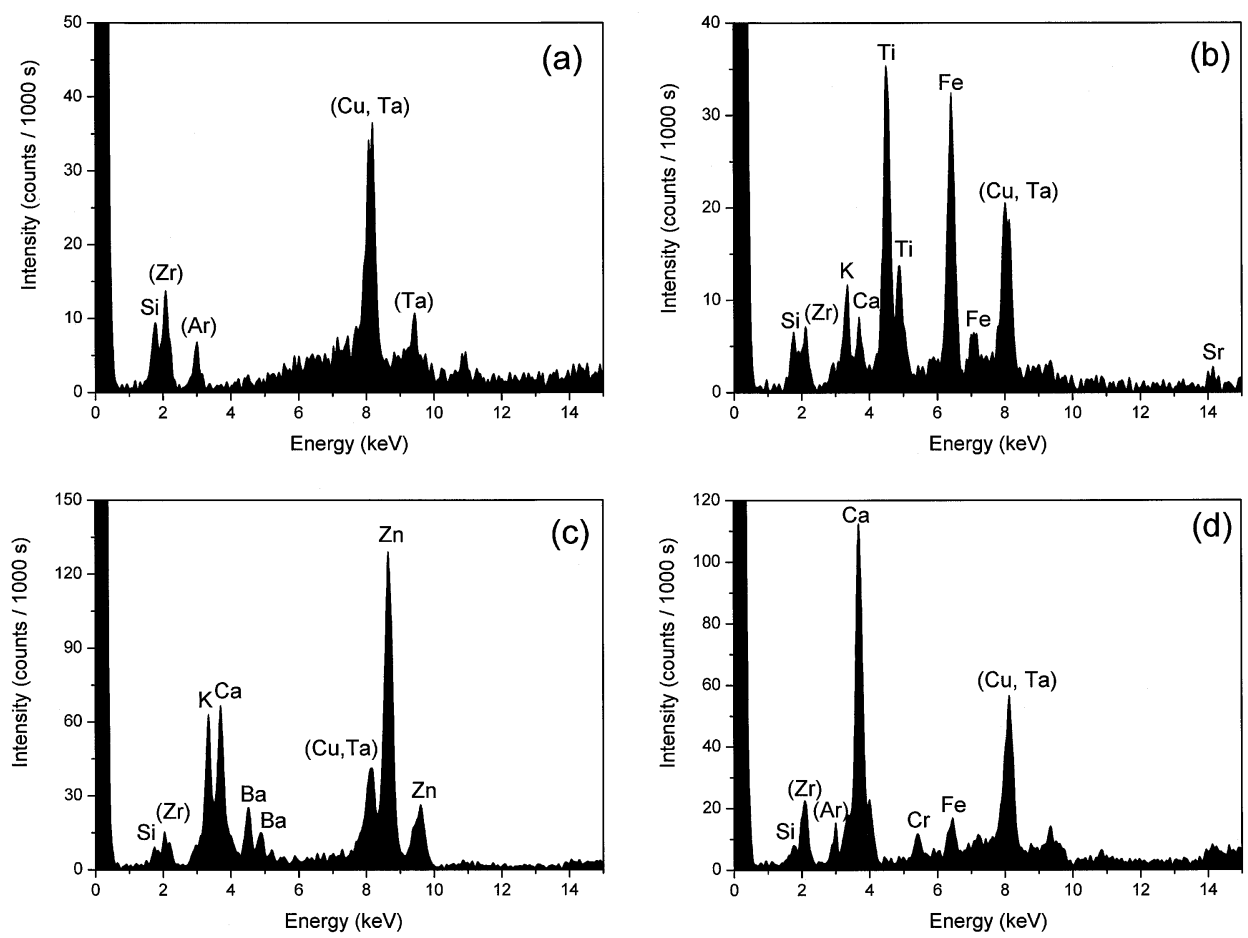

Fig. 2 XRF spectra of glass samples. (a) Quartz cuvet, (b) Test tube 1, (c) Slide glass, (d) Bottle.
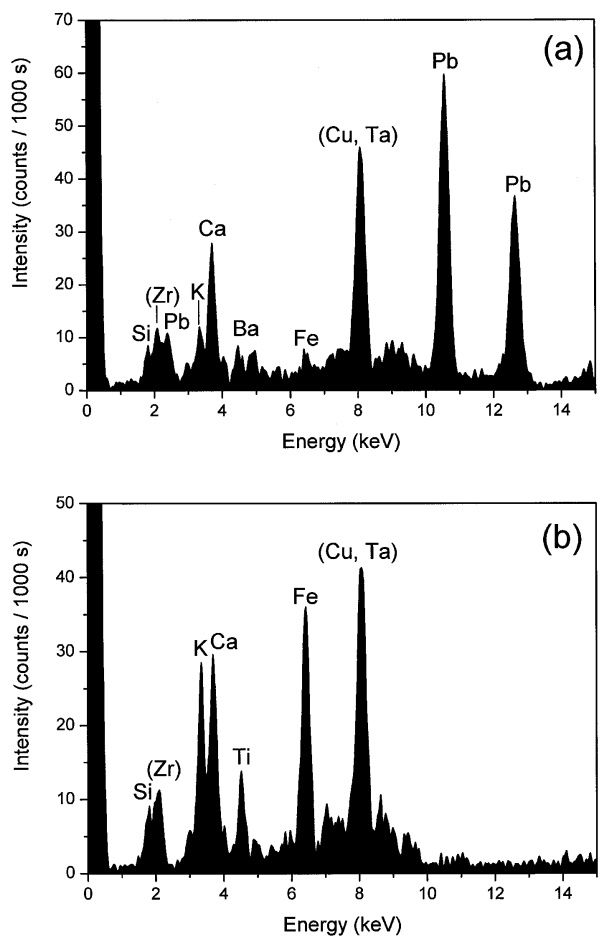

Fig. 3 XRF spectra of ceramic samples. (a) Dish 5, (b) Dish 6.

in air is a disadvantage to detect light elements.

\section{Conclusions}

Glass and ceramics were analyzed by the pyroelectric X-ray generator, and $\mathrm{Si}, \mathrm{K}, \mathrm{Ca}, \mathrm{Ti}, \mathrm{Cr}, \mathrm{Fe}, \mathrm{Zn}, \mathrm{Sr}, \mathrm{Ba}$, and $\mathrm{Pb}$ were detected in glass and ceramic samples. Light elements such as $\mathrm{Na}, \mathrm{Mg}$, and $\mathrm{Al}$ were not detected in all samples. Minor elements in glass such as $\mathrm{As}, \mathrm{Rb}, \mathrm{Sb}$, and $\mathrm{Pb}$ were not detected owing to the low content of these elements. The number of elements detected in each glass sample by the pyroelectric Xray generator was less than the number of elements detected by a conventional XRF spectrometer because of the low X-ray output of the pyroelectric X-ray generator and measurements in air. Notwithstanding this disadvantage, the XRF spectra of all the samples analyzed were different from one another and the samples were identified on the basis of spectrum differences (elements detected and their relative peak intensity). Of course strict identification cannot be carried out with this X-ray generator. That needs high sensitivity XRF analysis or other analytical methods. The pyroelectric X-ray generator can be used for preliminary screening to examine whether the two samples have the same main composition or not. If a difference on the composition is recognized, identification is finished and the conclusion that the two samples are different is obtained. If no difference on the composition is recognized, further analysis is needed to carry out identification of the two samples. This novel device has the capability for on-site screening of analytes.

Glass and ceramics contain $\mathrm{SiO}_{2}$ as principal compound. The pyroelectric X-ray generator shows the capability of analyzing glass and ceramics that are representative of nonmetallic inorganic material. This result indicates that the pyroelectric Xray generator can also be used for analysis of rock and soil whose composition is similar to glass and ceramics (i.e. Si matrix).

The pyroelectric X-ray generator is particularly suitable for portable XRF spectrometers because of the characteristics of small dimensions $(125 \mathrm{~mm} \times 45 \mathrm{~mm} \times 30 \mathrm{~mm})$, light weight $(210 \mathrm{~g})$ and dry battery drive $(9 \mathrm{~V})$. This X-ray generator has no limitation on sample dimensions. Large samples that cannot be put into a conventional XRF spectrometer can be analyzed by the use of a portable device. Though the sensitivity of 
portable devices is generally lower than the sensitivity of conventional XRF spectrometers owing to the low X-ray output and measurement in air, portable devices have an advantage of analyzing large samples and immovable samples that cannot be analyzed by conventional XRF spectrometers without destruction of the sample.

\section{Acknowledgements}

This work was partially supported by the Murata Science Foundation.

\section{References}

1. J. Kawai, N. Inada, and K. Maeda, Adv. X-Ray Chem. Anal., Jpn., 1997, 29, 203.

2. J. D. Brownridge, Nature, 1992, 358, 287.

3. J. D. Brownridge and S. Raboy, J. Appl. Phys., 1999, 86, 640.

4. J. Kawai, T. Yamada, and H. Fujimura, Bunseki Kagaku, 2004, 58, 183.

5. H. Ida and J. Kawai, Adv. X-Ray Chem. Anal., Jpn., 2004, 35,81 .

6. H. Ida and J. Kawai, Anal. Bioanal. Chem., 2004, 379, 735.

7. H. Ida and J. Kawai, Bunseki Kagaku, 2004, 53, 753.

8. C. Jokubonis, P. Wobrauschek, S. Zamini, M. Karwowski, G. Trnka, and P. Stadler, Spectrochim. Acta, 2003, B58,
627.

9. M. Milazzo, Nucl. Instrum. Methods Phys. Res., 2004, B213, 683 .

10. H. Bronk, S. Röhrs, A. Bjeoumikov, N. Langhoff, J. Schmalz, R. Wedell, H. E. Gorny, A. Herold, and U. Waldschläger, Fresenius J. Anal. Chem., 2001, 371, 307.

11. M. Wegstein, H. Urban, P. Rostam-Khani, A. Wittershagen, and B. O. Kolbesen, Spectrochim. Acta, 1997, B52, 1057.

12. F. Cariati, P. Fermo, S. Gilardoni, A. Galli, and M. Milazzo, Spectrochim. Acta, 2003, B58, 177.

13. D. Jembrih, M. Schreiner, M. Peev, P. Krejsa, and C. Clausen, Mikrochim. Acta, 2000, 133, 151.

14. M. Heck and P. Hoffmann, Mikrochim. Acta, 2002, 139, 71.

15. S. S. Ramos, F. B. Reig, J. V. G. Adelantado, D. J. Y. Marco, and A. D. Carbó, Anal. Bioanal. Chem., 2002, 373, 893.

16. A. Tsolakidou and V. Kilikoglou, Anal. Bioanal. Chem., 2002, 374, 566

17. S. S. Ramos, F. B. Reig, J. V. G. Adelantado, D. J. Y. Marco, and A. D. Carbó, Spectrochim. Acta, 2002, B57, 689.

18. J. J. LaBrecque, J. E. Vaz, J. M. Cruxent, and P. A. Rosales, Spectrochim. Acta, 1998, B53, 95.

19. A. Savitzky and M. J. E. Golay, Anal. Chem., 1964, 36, 1627.

20. J. Steinier, Y. Termonia, and J. Deltour, Anal. Chem., 1972, 44, 1906. 